\title{
Clinical, Laboratory, and Molecular Findings for 63 Patients With Severe Combined Immunodeficiency: A Decade's Experience
}

Fazlollahi MR' ${ }^{1}$, Pourpak $Z^{1}$, Hamidieh AA ${ }^{2}$, Movahedi $\mathrm{M}^{3}$, Houshmand $\mathrm{M}^{1,4}$, Badalzadeh $\mathrm{M}^{1}$, Nourizadeh $\mathrm{M}^{1}$, Mahloujirad $\mathrm{M}^{1}$, Arshi $\mathrm{S}^{5}$, Nabavi $\mathrm{M}^{5}$, Gharagozlou $\mathrm{M}^{3}$, Khayatzadeh $\mathrm{A}^{3}$, Dabbaghzade $\mathrm{A}^{6}$, Atarod $\mathrm{L}^{7}$, Zandieh $\mathrm{F}^{8}$, Sadeghi Shabestary $\mathrm{M}^{9}$, Mesdaghi $\mathrm{M}^{10}$, Mohammadzadeh I"1, Mahdaviani $\mathrm{SA}^{12}$, Eslamian $\mathrm{MH}^{13}$, Pesaran $\mathrm{F}^{1}$, Bahraminia $\mathrm{E}^{3}$, Abolnezhadian $\mathrm{F}^{14}$, Arij $\mathrm{Z}^{1}$, Moin $\mathrm{M}^{1}$

\footnotetext{
'Immunology Asthma and Allergy Research Institute (IAARI), Tehran University of Medical Sciences, Tehran, Iran ${ }^{2}$ Hematology-Oncology and Stem Cell Transplantation Research Center, Shariati Hospital, Tehran University of Medical Sciences, Tehran, Iran

${ }^{3}$ Department of Allergy and Clinical Immunology, Children's Medical Center, Tehran University of Medical Sciences, Tehran, Iran

${ }^{4}$ Department of Medical Genetics, National Institute of Genetic Engineering and Biotechnology (NIGEB), Tehran, Iran

${ }^{5}$ Department of Allergy and Clinical Immunology, Hazrat Rasoul Hospital, Iran University of Medical Sciences,

Tehran, Iran

${ }^{6}$ Department of Allergy and Clinical Immunology, Mazandaran University of Medical Sciences, Sari, Iran ${ }^{7}$ Department of Pediatrics, Imam Khomeini Hospital, Tehran University of Medical Sciences, Tehran, Iran ${ }^{8}$ Department of Allergy and Clinical Immunology, Bahrami Hospital, Tehran University of Medical Sciences, Tehran, Iran

${ }^{9}$ Department of Allergy and Clinical Immunology, Tabriz Children's Hospital, Tabriz University of Medical Sciences, Tabriz, Iran

${ }^{10}$ Department of Allergy and Clinical Immunology, Mofid Hospital, Shahid Beheshti University of Medical Sciences, Tehran, Iran

${ }^{11}$ Department of Immunology and Allergy, Amirkola Hospital, Babol University of Medical Sciences, Babol, Iran ${ }^{12}$ Pediatric Respiratory Diseases Research Center, National Research Institute of Tuberculosis and Lung Diseases (NRITLD), Shahid Beheshti University of Medical Sciences, Tehran, Iran

${ }^{13}$ Allergy and Clinical Immunology Group, Faculty of Medicine, Hamedan University of Medical Sciences,

Hamedan, Iran

${ }^{14}$ Department of Immunology and Allergy, Ahvaz University of Medical Sciences, Ahvaz, Iran
} 


\section{Abstract}

Introduction: Severe combined immunodeficiency (SCID) is a life-threatening pediatric disease. We report on the clinical evaluation, immunological assessment, molecular analysis, and outcomes of SCID patients in a tertiary referral center in Iran.

Methods: From January 2006 to December 2015, we performed a prospective cohort study in which initial screening and advanced immunological tests were carried out on patients suspected of having SCID. Genetic analysis was also performed to confirm the diagnosis. Results: A total of 63 patients were diagnosed with SCID (43 male [68.3\%]). The median age at onset and diagnosis and diagnostic delay were 40 and 110 and 60 days respectively. A total of 49 patients $(77.8 \%)$ had a history of BCG vaccination, and of these, onethird experienced BCG-associated complications. The most common clinical manifestations were pneumonia, recurrent oral candidiasis, chronic diarrhea, and failure to thrive. Of the thirteen patients who underwent hematopoietic stem cell transplantation, 8 survived and 5 died before they could receive the transplant. Most patients (34.9\%) were classified as having T-B-NK+ SCID and had a mutation in the RAG2 or RAG1 gene.

Conclusion: Autosomal recessive SCID is the most common type in Iranian patients. Providing high-quality training to physicians and patients' families to reduce the diagnostic delay should be prioritized. It is also important to raise awareness of live vaccination and to expand stem cell donor registries to speed up the transplantation process.

Key words: Severe combined immunodeficiency. Newborn screening. BCG complications. Stem cell transplantation.

\section{Resumen}

Introducción: La inmunodeficiencia combinada severa (SCID) es una grave enfermedad pediátrica que puede comprometer la vida del paciente. El artículo recoge la evaluación clínica e inmunológica, el análisis molecular y la supervivencia de los pacientes con SCID atendidos en un hospital de referencia de Irán.

Métodos: Desde enero de 2006 a diciembre de 2015, se realizó un estudio prospectivo en los pacientes con SCID en el que se realizó un screening inicial junto a diferentes análisis inmunológicos. Se realizó un análisis genético para confirmar el diagnóstico.

Resultados: Sesenta y tres pacientes fueron diagnosticados de SCID, cuarenta y tres $(63,8 \%)$ de los mismos eran varones. La mediana de la edad de inicio de la enfermedad, diagnóstico y retraso en su diagnóstico, fueron de 40, 110 y 60 días respectivamente. Cuarenta y nueve pacientes $(77,8 \%)$ recibieron vacunación con BCG y un tercio de los mismos presentó complicaciones como consecuencia de la misma. Las manifestaciones clínicas más frecuentes de estos pacientes fueron: neumonía, candidiasis oral recidivante, diarrea crónica y retraso en el crecimiento. Ocho de los treces pacientes que recibieron trasplante de progenitores hematopoyéticos, lograron sobrevivir. Los restantes pacientes fallecieron antes de poder recibir dicho trasplante. El 34,9\% de los pacientes tuvieron T-B-NK+ SCID y la mayoría de los pacientes eran portadores de mutaciones en los genes RAG2 o RAG1.

Conclusión: La variante autosómica recesiva de la SCID es la forma más común en los pacientes iraníes. Se debe considerar prioritario proporcionar una formación adecuada a los médicos y las familias para reducir el retraso en el diagnóstico. Es igualmente importante concienciar para evitar la vacunación con gérmenes vivos y expandir los registros de donantes de células madre para agilizar el trasplante de estos pacientes.

Palabras clave: Inmunodeficiencia combinada severa. Screening del recién nacido. Complicaciones BCG. Transplante de células madre.

\section{Introduction}

Severe combined immunodeficiency (SCID) is a prototype of primary immunodeficiency disease (PID). It is a heterogeneous, life-threatening syndrome comprising a group of rare and monogenic diseases [1].

The prevalence of SCID worldwide is estimated to be 1 in 50000 to 100000 live births [2]. However, the actual number of PIDs has been shown to be higher than previously reported, especially in countries such as Iran, which have a high rate of consanguinity [3], and in other countries, where a large number of early deaths of unknown cause have been reported [4]. It is difficult to determine the exact number of cases of SCID in Iran before conducting newborn screening for SCID, although it seems to be greater than that we initially thought [5].

SCID patients generally present severe and repeated infections by opportunistic microorganisms (eg, Pneumocystis jiroveci, Candida albicans, and cytomegalovirus), skin rashes, persistent diarrhea, and failure to thrive within the first year of life. SCID patients often need immediate pediatric emergency care $[1,6]$.
According to their fundamental defects, SCID patients are classified into 4 major groups: (1) imperfect function of pre-T-cell antigen receptor complex (eg, $\mathrm{CD} 3 \varepsilon / \delta / \zeta$ and $\mathrm{CD} 45$ ); (2) impaired signaling function based on common $\gamma$-chaindependent cytokine receptors, such as defects in the interleukin 2 receptor $\gamma$-chain, interleukin 7 receptor $\alpha$-chain, and Janus kinase 3; (3) V(D)J recombination defects (eg, Artemis and RAGI/ $R A G 2$ deficiency); and (4) early lymphocyte death mediated by purine metabolic dysfunction (ADA deficiency) [7].

Given the scarcity of publications on Iranian newborns with SCID, the aim of this study was to present the clinical features of SCID patients, available laboratory findings, and results of genetic analyses.

\section{Methods}

\section{Data Collection}

The study sample comprised 63 SCID patients referred to the Immunology, Asthma and Allergy Research Institute (IAARI) of Tehran University of Medical Sciences, Tehran, 
Iran from various health centers across the country. We conducted a prospective cohort study over a 10 -year period (January 2006 to December 2015).

A questionnaire was completed for each patient to record demographic information, history of complicated infections in the past and associated symptoms, family history of immunodeficiency, disseminated infection following BCG vaccination, and patients' outcomes. This study was approved by the Ethics Committee of the IAARI.

Patients were screened early, and an advanced immunological work-up was performed. This included a complete blood count, serum immunoglobulin levels ( $\mathrm{IgG}, \mathrm{IgA}$, $\operatorname{IgM}$, and $\operatorname{IgE}$ ) measured by nephelometry, lymphocyte count and immunophenotype analysis using flow cytometry (CD3, CD4, CD8, CD19, and CD16/56), lymphocyte proliferation response to phytohemagglutinin (PHA), nitro-blue tetrazolium (NBT) test, and the total hemolytic complement (CH50) assay.

Based on the guidelines of the Pan-American Group for Immunodeficiency and the European Society for Immunodeficiencies [8], the clinical diagnostic criteria included at least 1 invasive bacterial, viral, or fungal/opportunistic infection and/or persistent diarrhea, recurrent pneumonia, persistent thrush, as well as failure to thrive and/or affected family members. Patients with symptoms during the first year of life in whom HIV infection was ruled out were enrolled in the study. Participating patients had low or zero counts of CD3, CD4, or CD8 T cells (except for atypical SCID). Based on normal lymphocyte subsets in healthy children [9] and lymphocyte immunophenotyping, patients were classified into 5 groups, as follows: $\mathrm{T}^{-} \mathrm{B}^{-} \mathrm{NK}^{+} \mathrm{SCID}, \mathrm{T}^{-} \mathrm{B}^{-} \mathrm{NK}^{-} \mathrm{SCID}, \mathrm{T}^{-} \mathrm{B}^{+} \mathrm{NK}^{+}$ SCID, $\mathrm{T}^{-} \mathrm{B}^{+} \mathrm{NK}^{-} \mathrm{SCID}$, and atypical $\mathrm{T}^{+}$SCID.

\section{Genetic Analysis}

Molecular evaluations were performed for specific genes known to be involved in SCID (including IL2R,IL7RA, ADA, $R A G 1$, and $R A G 2$ ). Briefly, in patients with $\mathrm{T}^{-} \mathrm{B}^{-} \mathrm{NK}^{+}, \mathrm{T}^{-} \mathrm{B}^{-} \mathrm{NK}^{-}$, and $\mathrm{T}^{-} \mathrm{B}^{+} \mathrm{NK}^{+}$phenotypes, a genetic study was performed, respectively, for $R A G 1 / R A G 2, A D A$, and $I L 7 R A$. A genetic study of $R A G 1 / R A G 2$ was also performed for 3 atypical patients with the $\mathrm{T}^{+} \mathrm{B}^{-} \mathrm{NK}^{+}$phenotype. Males with the $\mathrm{T}^{-} \mathrm{B}^{+} \mathrm{NK}^{-}$phenotype were evaluated to assess mutations in $I L 2 R$. Genomic DNA was extracted from peripheral blood leukocytes. The exons and exon-intron boundaries were amplified by PCR runs with a final volume of $25 \mu \mathrm{L}$ containing $200 \mathrm{ng}$ of genomic DNA, 10 pmol of each primer, $100 \mu \mathrm{M}$ of dNTP, various concentrations of $\mathrm{MgCl} 2$, 1x Taq DNA polymerase buffer, and 2 U Taq DNA polymerase (Cinagene). Initial denaturation of genomic DNA was performed for 5 minutes at $95^{\circ} \mathrm{C}$, followed by 35 cycles of amplification as follows: 35 seconds at $95^{\circ} \mathrm{C}, 35$ seconds at $54-64^{\circ} \mathrm{C}$, and 30 seconds at $72^{\circ} \mathrm{C}$. After evaluation on $1.5 \%$ agarose gel, PCR products were sequenced.

The definitive diagnosis was made based on data from the clinical findings, immunological assessments, and molecular analysis.

\section{Statistical Analysis}

Questionnaire and laboratory data were analyzed using SPSS, version 16 (SPSS Inc). The data were presented using descriptive statistics (mean [SD], median [IQR]. The normality of quantitative variables was determined using KolmogorovSmirnov test. The independent-sample $t$ test (or Mann-Whitney test for variables with a nonnormal distribution) was applied to compare the means of 2 quantitative variables. Statistical significance was set at $P<.05$.

\section{Results}

During the study, 63 patients with SCID from 61 families were diagnosed and followed up. Most patients with a typical feature of SCID $(n=52,82.5 \%)$ had $\mathrm{CD}^{+}$T-cell counts $<500 / \mu \mathrm{L}$. Furthermore, a $\mathrm{CD}^{+}$T-cell count $<300 / \mu \mathrm{L}$ was found to be positive in $77.8 \%$ of patients. Table 1 shows the laboratory findings and cell counts for the different patient phenotypes. Lymphocytopenia $(<3000$ cells $/ \mu \mathrm{L})$ was present in $82.5 \%$ of patients. The median lymphocyte count was 1380 (602-2304) for all patients, including atypical SCID patients. The results of the other immunological assessments of phagocytic function (NBT) and complement activity (CH50) were normal in all patients. According to typical immunologic classifications based on the immunophenotyping findings, 22 patients (34.9\%) were classified as $\mathrm{T}^{-} \mathrm{B}^{-} \mathrm{NK}^{+} \mathrm{SCID}, 15(23.8 \%)$ as $\mathrm{T}^{-} \mathrm{B}^{-} \mathrm{NK}^{-}, 10$ $(15.9 \%)$ as $\mathrm{T}^{-} \mathrm{B}^{+} \mathrm{NK}^{+}, 9(14.3 \%)$ as $\mathrm{T}^{-} \mathrm{B}^{+} \mathrm{NK}^{-}$(X-linked SCID), and $7(11.1 \%)$ as atypical SCID (T+ SCID).

Forty-three patients $(68.3 \%)$ were male. Consanguinity was found in $87.3 \%(n=55)$ of patients' families. A positive family history of SCID was recorded in 34 patients (54\%), and most families had only 1 child with SCID. The mean age at onset and diagnosis was 52 (48) and 113 (90), and the median age was 40 (15-60) and 110 (45-150) days, respectively. Interestingly, mean and median time to diagnosis decreased to 97 (85) and $60(35-150)$ days in the second half of the study.

Except for 2 patients who were diagnosed before the onset of symptoms based on the death of a sibling, the median diagnostic delay for the remaining 61 patients was 60 (15.5-90) days. Similarly, the median diagnostic delay decreased to 45 (13.7-60) days in the second half of the study. In addition, the difference in diagnostic delay between patients with a positive family history of SCID (45 [5.5-101]) and patients with a negative family history of SCID (60 [33.5-90]) was only 15 days.

In total, 49 patients had received a BCG vaccination $(77.8 \%)$, and subsequent localized complications (adenitis) were observed in $22(44.9 \%)$, of whom 14 patients had disseminated infection (BCGosis). Among patients with a positive family history of PID, about $65 \%$ had received BCG vaccines. Since the complications were not seen in all vaccinated patients, the median absolute numbers of T, B, and NK cells at the time of diagnosis in patients with complications of the BCG vaccine (except for atypical patients) were evaluated. The respective median absolute counts of CD3, CD19, and CD16 ${ }^{+}$CD56 cells in SCID patients with BCG complications were 329 (124-748), 73 (7.5-711), and 69 (14-139), whereas in SCID patients without localized or disseminated BCG complications, the counts were 23 (9-114), 8 (3-426), and 117 (31-336), respectively. However, no significant differences were found between these 2 groups of patients.

In the present study, the most common clinical manifestations were pneumonia $(n=49,77.8 \%)$, recurrent oral candidiasis $(n=29,46 \%)$, chronic diarrhea $(n=15,23.8 \%)$, failure to thrive $(n=13,20.6 \%)$, and oral ulcer $(n=10,15.4 \%)$. 


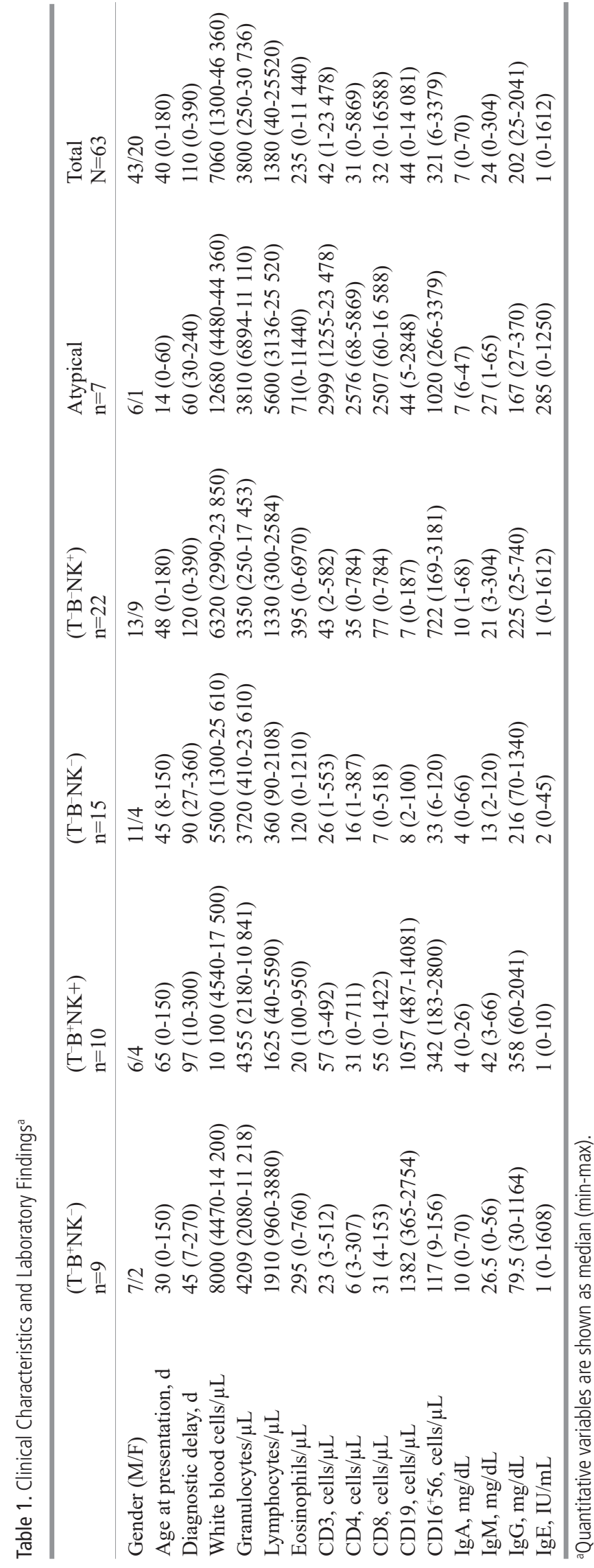

Prophylaxis (antituberculosis, antibacterial, antiviral, and antifungal) was administered in 14 (22.2\%), 36 (57.1\%), 13 $(20.6 \%)$, and $22(34.9 \%)$ patients, respectively. Intravenous immunoglobulin was administered to 43 patients $(68.3 \%)$.

During the study period, appropriate donors were found for 21 patients, and 13 underwent hematopoietic stem cell transplantation (HSCT). However, HSCT was able to rescue only 8 patients $(12.7 \%)$, who are still alive. The remaining 5 patients died of graft-versus-host disease or sepsis following transplantation. The mean age at the time of transplantation was about 8.3 months (range, 3-13 months). The mean survival time after transplantation until the end of this study was 17.7 months (range, 2-63 months). Overall, 50 of 63 patients (87.3\%) died because suitable donors were not found.

The lymphocyte proliferation response to PHA was assessed in 11 patients. A low response was found in 10 cases. In spite of a mutation found in the $R A G 2$ gene in the remaining patient, the response was normal $(>50 \%)$.

Although mutation analysis was performed for 33 patients (53\%), defects due to mutations were detected in only 17 . Fourteen different mutations, including 5 novel mutations, were identified. As shown in Table 2, most alterations were detected in RAG2 and RAG1.

\section{Discussion}

To our knowledge, this is the first comprehensive national report from Iran to show the clinical manifestations and laboratory and molecular findings for a large sample of patients with SCID. We found that most patients (34.9\%) were positive for NK cells but negative for both $\mathrm{T}$ and $\mathrm{B}$ cells $\left(\mathrm{T}^{-} \mathrm{B}^{-} \mathrm{NK}^{+}\right)$. The genetic analysis performed in $53 \%$ of patients revealed that most alterations were in $R A G 1$ and $R A G 2$ and that the XL-SCID group had the lowest number of patients $(14 \%)$. These findings are in contrast with reports from Europe and America [10], possibly owing to genetic variations between populations and a higher rate of consanguinity in Iran.

SCID is similar to another common PID in Iran, namely, chronic granulomatosis disease, which is more frequently autosomal recessive than $\mathrm{X}$-linked [11]. The dominant phenotype of SCID varies according to the country. For example, in China, 25 of 44 SCID patients had X-linked SCID [12], and in Serbia and Montenegro, 12 of 21 patients with SCID and Omenn syndrome belonged to the $\mathrm{T}^{-} \mathrm{B}^{-} \mathrm{NK}^{+}$ SCID phenotype; 11 had mutations in $R A G 1$ or RAG2 and 1 had mutations in the Artemis gene [3]. In Greece, 12 of 30 SCID patients $(40 \%)$ were $\mathrm{T}^{-} \mathrm{B}^{-} \mathrm{NK}^{+}[13]$.

In this study, the median age at the onset of symptoms and the age of diagnosis were 40 and 110 days, respectively. According to a previous report from Iran in 2008 [5], the mean age of diagnosis in Iranian SCID patients was 150 (20) days, which has fallen to less than 4 months during the last decade. Therefore, reducing the age at diagnosis to lower than 4 months in Iran is a valuable achievement compared with other countries such as Canada (4.2 months), Brazil (6.1 months), and Serbia (4 months) [14-16]. Our results also indicated that the median diagnostic delay reached 60 days ( 2 months), which was in accordance with reports from China (2.6 months), 


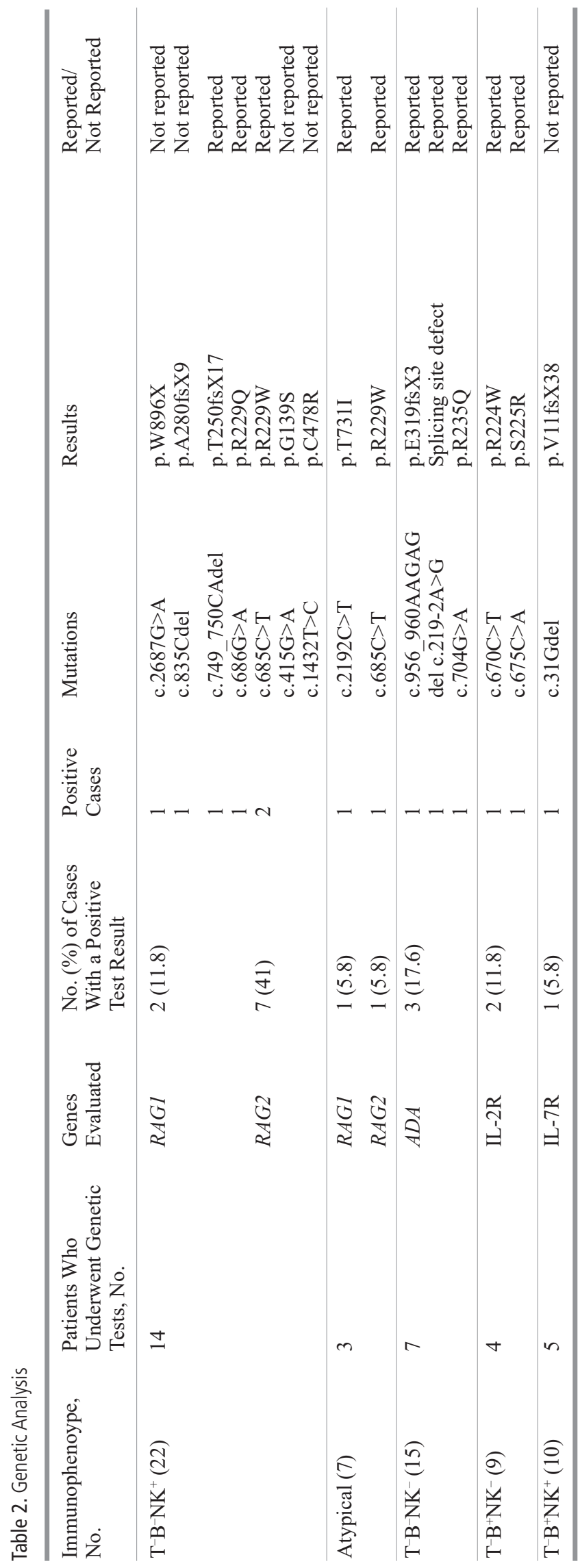

Serbia (2 months), and the Netherlands (2 months) [12 15 17], and better than Brazil (4.2 months) [16].

According to Roifman et al [18], a $\mathrm{CD}^{+} \mathrm{T}$-cell count $<500 / \mu \mathrm{L}$ is the most specific and sensitive parameter for separating patients with SCID from those with combined immunodeficiency. The authors also explained that a significant decrease in the response to the PHA test was found in all patients with $\mathrm{CD}^{+} \mathrm{T}$ cells $<500 / \mu \mathrm{L}$, although they hypothesized that the CD3 count might be normal in patients with profound T-cell dysfunction. Similarly, most of our patients were considered to have typical SCID in terms of the relevant feature of presenting $\mathrm{CD}^{+} \mathrm{T}$-cell counts $<500 /$ $\mu \mathrm{L}$. Nevertheless, new diagnostic criteria for SCID proposing $<300 / \mu \mathrm{L}$ as the cut-off for SCID [18] have opened the debate on setting the most accurate value. Therefore, we also evaluated patients with $\mathrm{CD}^{+}<300 / \mu \mathrm{L}$, although we found no significant differences compared with patients with $\mathrm{CD}^{+}<500 / \mu \mathrm{L}(77.8 \%$ vs $82.5 \%$ ).

Most patients in our study had typical clinical manifestations and laboratory findings, including lymphopenia and low Ig levels except for maternal IgG; however, some had a high absolute lymphocyte count and normal Ig levels. The fact that these patients had an atypical presentation of lymphocyte subsets and normal serum Ig suggests that they comprise a subgroup of SCID patients with normal B lymphocytes who have the potential to produce measurable amounts of serum IgE and eosinophils $[2,7]$. In atypical cases, different clinical and immunological features were described, even within one family [19].

Pulmonary diseases were the most relevant complication $(80 \%)$ in the patients we report. The other affected organs were the reticuloendothelial system, the gastrointestinal tract, skin, bones and joints, and the ear, nose, and throat. However, autoimmune diseases were not found.

We observed BCG-associated complications in only onethird of the patients, possibly because of factors such as genetic differences, the immune repertoire, vaccine ingredients, and lower T-cell counts [20] (the last factor was not confirmed in our study and requires further investigation).

Both BCG and other live attenuated vaccines are contraindicated in infants with SCID [20]. To avoid inoculating the patients with a positive family history ( $65 \%$ of patients in our study), awareness of the dangers of vaccination needs to be increased both in physicians and in patients' families.

A recent approach to the early diagnosis of SCID involves the implementation of a newborn screening program (T-cell receptor excision circles assay) to hasten treatment and prevent the use of live vaccines in immunocompromised children [21-23].

The main limitations of the present study were the lack of laboratory facilities for performing genetic studies and the fact that the lymphocyte proliferation test was not performed in all participants. Nevertheless, our findings in this long-term study with a large sample may be of considerable value.

\section{Conclusion}

We found that autosomal recessive SCID was the most frequent inherited type of SCID in Iranian patients. However, diagnostic delay and the lack of suitable donors are the main 
causes of the high mortality observed among SCID patients. Increasing physicians' awareness of the onset of serious infections and irreversible outcomes of BCG vaccination could improve the management of these patients.

\section{Acknowledgments}

We would like to thank N Sabetkish, R Shokouhi Shoormasti, S Najafi, S Khadivi, and L Shakerian for their excellent help and contribution to the study.

\section{Funding}

The authors declare that no funding was received for the present study.

\section{Conflicts of Interest}

The authors declare that they have no conflicts of interest.

\section{References}

1. Rosen FS. Severe combined immunodeficiency: a pediatric emergency. J Pediatr 1997;130:345-6

2. Puck JM, Group SNSW. Population-based newborn screening for severe combined immunodeficiency: steps toward implementation. J Allergy Clin Immunol 2007;120:760-8.

3. Rezaei N, Pourpak Z, Aghamohammadi A, Farhoudi A, Movahedi M, Gharagozlou $M$, et al. Consanguinity in primary immunodeficiency disorders; the report from Iranian Primary Immunodeficiency Registry. Am J Reprod Immunol 2006;56:145-51.

4. Chapel H, Prevot J, Gaspar HB, Espanol T, Bonilla FA, Solis L, et al. Primary immune deficiencies - principles of care. Front Immunol 2014;5:627.

5. Yeganeh $M$, Heidarzade M, Pourpak Z, Parvaneh N, Rezaei N, Gharagozlou $M$, et al. Severe combined immunodeficiency: a cohort of 40 patients. Pediatr Allergy Immunol 2008;19:303-6.

6. Rivers L, Gaspar HB. Severe combined immunodeficiency: recent developments and guidance on clinical management. Arch Dis Child 2015;100:667-72.

7. Sponzilli I, Notarangelo LD. Severe combined immunodeficiency (SCID): from molecular basis to clinical management. Acta Biomed 2011;82:5-13.

8. Conley ME, Notarangelo LD, Etzioni A. Diagnostic criteria for primary immunodeficiencies. Representing PAGID (PanAmerican Group for Immunodeficiency) and ESID (European Society for Immunodeficiencies). Clin Immunol 1999;93:190-7.

9. Shearer WT, Rosenblatt HM, Gelman RS, Oyomopito R, Plaeger $\mathrm{S}$, Stiehm ER, et al. Lymphocyte subsets in healthy children from birth through 18 years of age: the Pediatric AIDS Clinical Trials Group P1009 study. J Allergy Clin Immunol 2003;112:973-80.

10. Picard C, Moshous D, Fischer A. The Genetic and Molecular Basis of Severe Combined Immunodeficiency. Current Pediatrics Reports 2015;3:22-33.

11. Fattahi F, Badalzadeh M, Sedighipour L, Movahedi M, Fazlollahi MR, Mansouri SD, et al. Inheritance pattern and clinical aspects of 93 Iranian patients with chronic granulomatous disease. J Clin Immunol 2011;31:792-801.

12. Yao CM, Han XH, Zhang YD, Zhang $H$, Jin YY, Cao RM, et al. Clinical characteristics and genetic profiles of 44 patients with severe combined immunodeficiency (SCID): report from Shanghai, China (2004-2011). J Clin Immunol 2013;33:526-39.

13. Michos A, Tzanoudaki M, Villa A, Giliani S, Chrousos G, Kanariou M. Severe combined immunodeficiency in Greek children over a 20-year period: rarity of gammac-chain deficiency (X-linked) type. J Clin Immunol 2011;31:778-83.

14. Rozmus J, Junker $A$, Thibodeau ML, Grenier D, Turvey SE, Yacoub $W$, et al. Severe combined immunodeficiency (SCID) in Canadian children: a national surveillance study. J Clin Immunol 2013;33:1310-6.

15. Pasic S, Vujic D, Veljkovic D, Slavkovic B, Mostarica-Stojkovic $M$, Minic $P$, et al. Severe combined immunodeficiency in Serbia and Montenegro between years 1986 and 2010: a singlecenter experience. J Clin Immunol 2014;34:304-8.

16. Mazzucchelli JT, Bonfim C, Castro GG, Condino-Neto AA, Costa $\mathrm{NM}$, Cunha L, et al. Severe combined immunodeficiency in Brazil: management, prognosis, and BCG-associated complications. J Investig Allergol Clin Immunol 2014;24:184-91.

17. de Pagter AP, Bredius RG, Kuijpers TW, Tramper J, van der Burg M, van Montfrans J, et al. Overview of 15-year severe combined immunodeficiency in the Netherlands: towards newborn blood spot screening. Eur J Pediatr 2015;174:118388.

18. Shearer WT, Dunn E, Notarangelo LD, Dvorak CC, Puck JM, Logan BR, et al. Establishing diagnostic criteria for severe combined immunodeficiency disease (SCID), leaky SCID, and Omenn syndrome: the Primary Immune Deficiency Treatment Consortium experience. J Allergy Clin Immunol 2014; 133:1092-8

19. Wada $T$, Toma $T$, Yasui $M$, Inoue $M$, Kawa $K$, Imai $K$, et al Different Clinical Phenotypes in 2 Siblings With X-Linked Severe Combined Immunodeficiency. J Investig Allergol Clin Immunol 2016;26:63-5.

20. Marciano BE, Huang CY, Joshi G, Rezaei N, Carvalho BC, Allwood $Z$, et al. BCG vaccination in patients with severe combined immunodeficiency: complications, risks, and vaccination policies. J Allergy Clin Immunol 2014;133:1134-41.

21. Kwan A, Abraham RS, Currier R, Brower A, Andruszewski K, Abbott JK, et al. Newborn screening for severe combined immunodeficiency in 11 screening programs in the United States. JAMA 2014;312:729-38.

22. Nourizadeh $M$, Borte $S$, Fazlollahi MR, Hammarstrom $L_{\text {, }}$ Pourpak Z. A New IL-2RG Gene Mutation in an X-linked SCID Identified through TREC/KREC Screening: a Case Report. Iran J Allergy Asthma Immunol 2015;14:457-61.

23. Puck JM. Neonatal Screening for Severe Combined Immunodeficiency (SCID). Curr Opin Pediatr 2011;23:667-73.

- Manuscript received August 6, 2016; accepted for publication February 6, 2017.

\section{Mostafa Moin}

Immunology Asthma and Allergy Research Institute Tehran University of Medical Sciences, Tehran, Iran E-mail: mmoin@tums.ac.ir 